\title{
Efficiency and Effectiveness of a Rotation-Shaped Fin Having the Cross-Section Area Dependent on the One- Dimensional Position
}

\author{
Petrus Kanisius Purwadi, Yunus Angga Vantosa, Sudi Mungkasi \\ \{pur@usd.ac.id ${ }^{1}$, vantosa21@gmail.com², sudi@usd.ac.id ${ }^{3}$ \} \\ Department of Mechanical Engineering, Universitas Sanata Dharma, Yogyakarta, Indonesia ${ }^{1,2}$, \\ Department of Mathematics, Universitas Sanata Dharma, Yogyakarta, Indonesia ${ }^{3}$
}

\begin{abstract}
This article reports research results on the efficiency and effectiveness of a rotation-shaped fin. The cross section area of the fin is dependent on the one-dimensional position. The computation is based on the conservation of energy. Using a finite difference method, we compute the temperature of the fin at every time step. We focus our investigation in unsteady state problems. We obtain that when the state is unsteady, the efficiency and effectiveness of the fin are affected by the thermal diffusivity of the material. When the state is steady, the efficiency and effectiveness of the fin is affected by the thermal conductivity of the material. The velocity of the fluid acrosses the fin influences the efficiency and effectiveness of the fin, that is, the greater the speed of fluid flowing across the fins, the lower the efficiency and effectiveness of the fin.
\end{abstract}

Keywords: Efficiency, effectiveness, steady state, unsteady state, rotation-shaped fin.

\section{Introduction}

Fin serves to speed up heat transfer from the fin to the fluid around the fin [1]. With a fin, the surface area of the object becomes larger [2]. The larger the surface area of the object in contact with the fluid, the greater the heat transfer of the convection [3]. Fins are usually installed in heat exchangers, such as evaporators, condensers, radiators, fuel motor cylinder blocks, heat sinks and other electronic equipments.

The important thing that must be known in the design and use of fins is the level of fin efficiency and fin effectiveness [43]. The efficiency of fins is the ratio between the heat released by the actual fin and the heat released by the fins when the entire fin has the same temperature as the temperature at the base of the fin. While the effectiveness of fins is the ratio between the heat released by the actual fin and the heat released if there are no fins.

It is not easy to do analytical calculations of efficiency and effectiveness in a rotationshaped fin that have a non-fixed cross-sectional area with the properties of thermal conductivity of materials that change with temperature in unsteady state problems. Whereas if done experimentally, the costs are relatively high and it takes a long time. One easy way to solve this problem is to use computational methods, such as, an explicit finite difference method. In this paper we show how to calculate the efficiency of the fin and the effectiveness of the fins using an explicit finite difference method. In addition, we investigate the influences of the fin material 
and velocity of the fluid flowing across the fin to the efficiency and effectiveness of the fin in unsteady state problems.

Therefore, this paper discusses: (a) how to calculate the distribution of temperature, heat flow rate, efficiency and effectiveness, with the thermal conductivity of the material changes to the temperature in unsteady state problems, using the finite difference method; (b) how the fin material and flow velocity influence the fluid crossing the fin to the value of the efficiency and effectiveness of the fin. This paper is based on Vantosa [1].

The fin geometry is assumed to be in the form of a rotating object, with the radius of the position function is as shown in Figure 1. Here the fin length is denoted L. The fin radius of the position function is expressed by the equation $r=\mid 0.001\left(\sqrt{x^{5}}-6 \mid\right.$ for $x=0$ up to $x=0.1$. The base diameter of the fin is $\mathrm{D}$, and the fin end diameter is $\mathrm{d}$. The thermal conductivity of the fin is a function of the temperature or $k=k(T)$. The temperature of fluid around the fin is represented by $T_{\infty}$. The convective heat transfer coefficient is $h$.

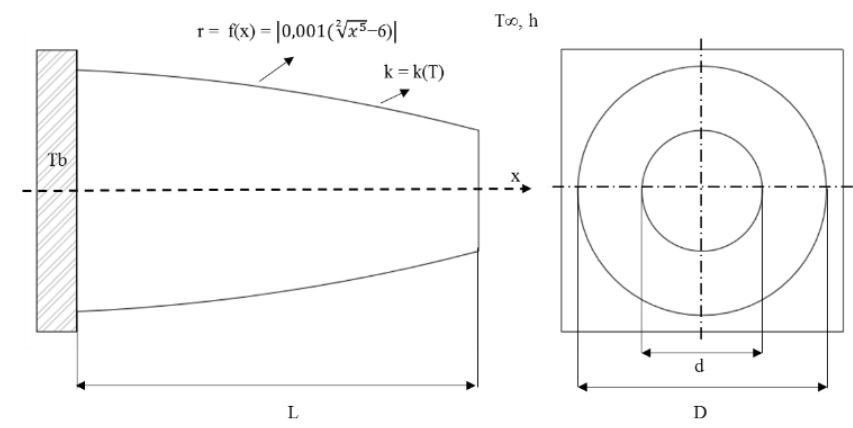

Fig. 1. Ilustration of the geometry of the rotation-shaped fin

The mathematical model that we use to determine the temperature $T(x, t)$ at position $0<$ $x<L$ when $t>0$, is presented in Equation (1). This equation is derived from the energy balance that occurs in the control volume of the fin.

$$
\frac{\partial}{\partial x}\left[k(T(x, t)) \cdot A c(x) \cdot \frac{\partial T(x, t)}{\partial x}\right]-h \cdot \frac{d A s(x)}{d x} \cdot\left(T(x, t)-T_{\infty}\right)=\rho \cdot c \cdot \frac{d V(x)}{d x} \cdot \frac{\partial T(x, t)}{\partial t}
$$

In Equation (1) we use the following convention :

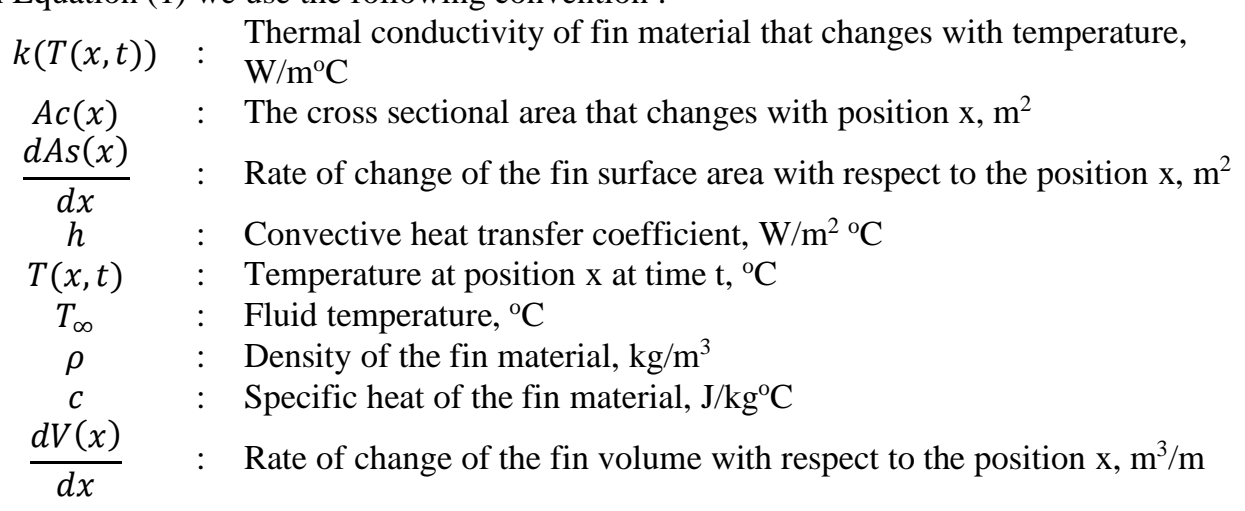


$x \quad$ : Position with respect to the base of the fin, $\mathrm{m}$

$t \quad:$ Time variable, $\mathrm{s}$

We use the following assumptions:

1. The thermal conductivity of the fin material changes with temperature, $k=k(T)$.

2. Specific mass and specific heat of the fin material do not change with temperature, and they are uniform.

3. Changes in volume and shape of the fin due to temperature changes are ignored.

4. The temperature of the fluid around the fin is constant and uniformly distributed.

5. The fin base temperature is kept constant over time, amounting to $T=T_{b}$.

6. The initial temperature of the fin is evenly or uniformly the same as the base temperature of the fins which is equal to $T=T_{i}=T_{b}$.

7. The convection heat transfer coefficient is fixed and evenly distributed, over time.

8. The speed of fluid flow around the fin is considered uniform and fixed over time.

9. The direction of heat transfer of conduction is only in the $\mathrm{x}$ direction, perpendicular to the fin base (one-dimensional case).

10. There is no energy generation in the fin $(\dot{\mathrm{q}}=0)$.

11. Radiation heat transfer is ignored.

The calculation steps are carried out in the following order: (1) calculation of the temperature of the fin or $T(x, t)$ in unsteady state; (2) calculating the heat flow released on the fin in unsteady state; (3) calculating the efficiency of the fin in unsteady state; (4) calculation of the effectiveness of the fin in unsteady state. Figure 2 shows that the fin is divided into $\mathrm{m}$ control volumes, with $m=101$. At time $t$, each control volume has a uniform temperature, even though each volume of control has different temperatures. The numerical equation for the calculation of temperature in each control volume can be derived using the principle of energy balance.

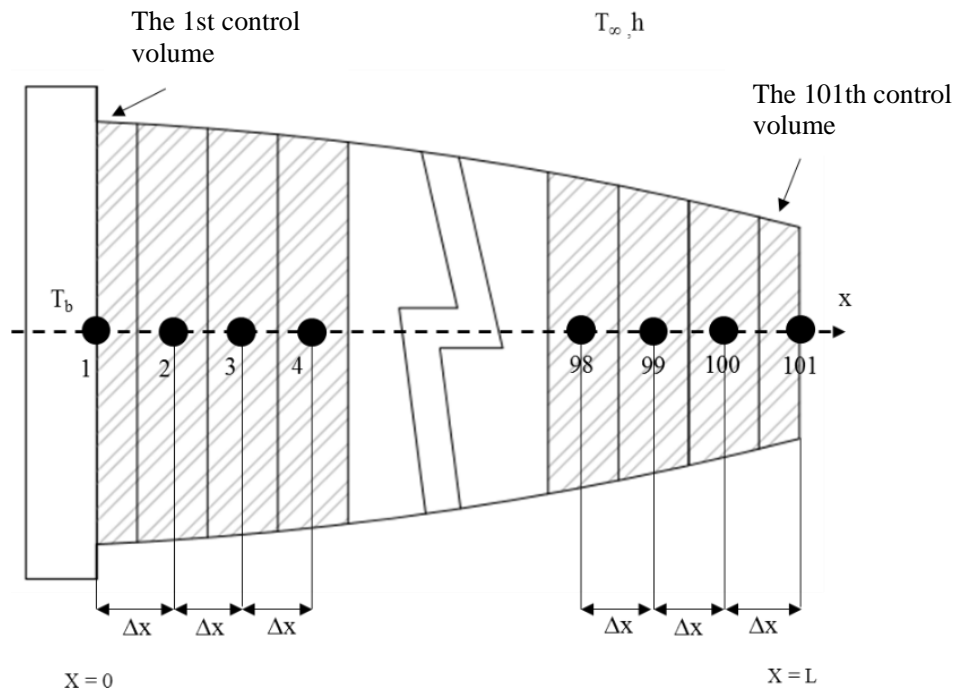

Fig. 2. Control volumes of the considered fin 
The initial condition of the fin (at $t=0$ ), from the base of the fin to the tip of the fin has a uniform temperature, equal to $T_{i}$, or can be expressed by Equation (2). This equation applies to $0 \leq x \leq L$, when $t=0$.

$$
T(x, 0)=T_{i}
$$

The temperature of the fin base (control volume $i=1$ ) is given by

$$
\mathrm{T}_{1}^{\mathrm{n}+1}=\mathrm{T}_{\mathrm{b}}
$$

We use an explicit finite difference method to calculate the temperature in unsteady state, in each control volume located between the base of the fin and the tip of the fin (or at the control volume $i=2,3,4, \ldots, m-1)$. Th finite difference scheme is given by Equation (4):

$$
\begin{gathered}
\mathrm{T}_{\mathrm{i}}^{\mathrm{n}+1}=\frac{\Delta \mathrm{t}}{\rho c \Delta \mathrm{xV}_{\mathrm{i}}}\left[\mathrm{k}_{\mathrm{i}-1 / 2}^{\mathrm{n}} \cdot \mathrm{A}_{\mathrm{c}, \mathrm{i}-1 / 2}\left(\mathrm{~T}_{\mathrm{i}-1}^{\mathrm{n}}-\mathrm{T}_{\mathrm{i}}^{\mathrm{n}}\right)+\mathrm{k}_{\mathrm{i}+1 / 2}^{\mathrm{n}} \cdot \mathrm{A}_{\mathrm{c}, \mathrm{i}+1 / 2}\left(\mathrm{~T}_{\mathrm{i}+1}^{\mathrm{n}}-\mathrm{T}_{\mathrm{i}}^{\mathrm{n}}\right)\right. \\
\left.+\mathrm{h} \Delta \mathrm{xA}_{\mathrm{s}, \mathrm{i}}\left(\mathrm{T}_{\infty}-\mathrm{T}_{\mathrm{i}}^{\mathrm{n}}\right)\right]+\mathrm{T}_{\mathrm{i}}^{\mathrm{n}}
\end{gathered}
$$

Equation (4) has a stability condition which is stated by Equation (5):

$$
\Delta t \leq \frac{\rho V_{i} \Delta x c}{\left(k_{i-1 / 2}^{n} A_{c, i-1 / 2}\right)+\left(k_{i+1 / 2}^{n} A_{c, i+1 / 2}\right)+\left(h \Delta x A_{s i}\right)}
$$

To calculate the temperature at the tip of the fin (or in the volume of control $i=m$ ) we use Equation (6). Note that in this paper $m=101$.

$$
\begin{aligned}
\mathrm{T}_{\mathrm{i}}^{\mathrm{n}+1}=( & \left.\frac{\Delta \mathrm{t}}{\rho \cdot \mathrm{c} \cdot \Delta \mathrm{x} \cdot \mathrm{V}_{\mathrm{i}}}\right)\left[\mathrm{k}_{\mathrm{i}-1 / 2}^{\mathrm{n}} \mathrm{A}_{\mathrm{c}, \mathrm{i}-1 / 2}\left(\mathrm{~T}_{\mathrm{i}-1}^{\mathrm{n}}-\mathrm{T}_{\mathrm{i}}^{\mathrm{n}}\right)+\mathrm{h} \Delta \mathrm{xA} \mathrm{A}_{\mathrm{c}, \mathrm{i}}\left(\mathrm{T}_{\infty}-\mathrm{T}_{\mathrm{i}}^{\mathrm{n}}\right)\right. \\
& \left.+\mathrm{h} \Delta \mathrm{x} \mathrm{A}_{\mathrm{s}, \mathrm{i}}\left(\mathrm{T}_{\infty}-\mathrm{T}_{\mathrm{i}}^{\mathrm{n}}\right)\right]+\mathrm{T}_{\mathrm{i}}^{\mathrm{n}}
\end{aligned}
$$

Equation (6) has a stability condition which is stated by Equation (7):

$$
\Delta \mathrm{t} \leq \frac{\rho V_{\mathrm{i}} \Delta \mathrm{x} \mathrm{c}}{\left(k_{i-1 / 2}^{n} \mathrm{~A}_{\mathrm{c}, \mathrm{i}-1 / 2}\right)+\left(\mathrm{h} \cdot \Delta \mathrm{x} \cdot \mathrm{A}_{\mathrm{c}, \mathrm{i}}\right)+\left(\mathrm{h} \Delta \mathrm{xA}_{\mathrm{s}, \mathrm{i}}\right)}
$$

In Equations (2), (3), (4), (5), (6) and (7) we have the following conventions:

$\begin{array}{lll}\mathrm{T}_{\mathrm{i}}^{\mathrm{n}+1} & : & \text { Temperature at position } \mathrm{i}, \text { at the } \mathrm{n}+1 \text { iteration, }{ }^{\circ} \mathrm{C} \\ \mathrm{T}_{\mathrm{i}}{ }^{\mathrm{n}} & : & \text { Temperature at position } \mathrm{i} \text {, at the } \mathrm{n} \text { iteration, }{ }^{\circ} \mathrm{C} \\ \mathrm{T}_{\mathrm{i}-1}^{\mathrm{n}} & : & \text { Temperature at position } \mathrm{i}-1 \text {, at the } \mathrm{n} \text { iteration, }{ }^{\circ} \mathrm{C} \\ \mathrm{T}_{\mathrm{i}+1}^{\mathrm{n}} & : & \text { Temperature at position } \mathrm{i}+1 \text {, at the } \mathrm{n} \text { iteration, }{ }^{\circ} \mathrm{C} \\ T_{\infty} & : & \text { Fluid temperature around the fin, }{ }^{\circ} \mathrm{C} \\ \Delta \mathrm{t} & : & \text { Time step, from the } \mathrm{n} \text { until } \mathrm{n}+1 \text { iteration, } \mathrm{s} \\ \Delta x & : & \text { Cell width or the space step, } \mathrm{m} \\ \mathrm{Vi} & : & \text { Volume of the control volume at position } \mathrm{i}, \mathrm{m}^{3} \\ \mathrm{~A}_{\mathrm{s}, \mathrm{i}} & : & \text { Fin surface area of control volume in contact with fluid across the fin, } \mathrm{m}^{2}\end{array}$




$\begin{array}{lll}\mathrm{A}_{\mathrm{c}, \mathrm{i}} & : & \text { Fin cross-section area at position } \mathrm{i}, \mathrm{m}^{2} \\ \mathrm{~A}_{\mathrm{c}, \mathrm{i}-1 / 2} & : & \text { Fin cross-section area at position } \mathrm{i}_{\mathrm{i}-1 / 2}, \mathrm{~m}^{2} \\ \mathrm{~A}_{\mathrm{c}, \mathrm{i}+1 / 2} & : & \text { Fin cross-section area at position } \mathrm{i}_{\mathrm{i}+1 / 2}, \mathrm{~m}^{2} \\ \mathrm{k}_{\mathrm{i}-1 / 2}^{\mathrm{n}} & : & \text { Thermal conductivity of material in position } \mathrm{i}_{\mathrm{i}-1 / 2} \text {, at } \mathrm{n} \text { iteration, } \mathrm{W} / \mathrm{m}{ }^{0} \mathrm{C} \\ \mathrm{k}_{\mathrm{i}+1 / 2}^{\mathrm{n}} & : & \text { Thermal conductivity of material in position } \mathrm{i}_{\mathrm{i}+1 / 2} \text {, at } \mathrm{n} \text { iteration, } \mathrm{W} / \mathrm{m}{ }^{0} \mathrm{C} \\ \rho & : & \text { Density of the fin material, } \mathrm{kg} / \mathrm{m}^{3} \\ \mathrm{c} & : & \text { Specific heat of the fin material, } \mathrm{J} / \mathrm{kg}{ }^{0} \mathrm{C} .\end{array}$

If the temperature distribution of the fin is known, the actual heat released by the fin ( $\mathrm{q}_{\text {actual }}$ ) into the fluid across the fin can be calculated using Equation (8). The maximum heat that can be removed from the fin ( $\left.q_{\text {ideal }}\right)$ can be calculated using Equation (9).

$$
\begin{gathered}
\mathrm{q}_{\text {aktual }}^{\mathrm{n}}=\mathrm{h} \sum_{\mathrm{i}=1}^{\mathrm{m}}\left(\mathrm{A}_{\mathrm{s}, \mathrm{i}}\left(\mathrm{T}_{\mathrm{i}}^{\mathrm{n}}-\mathrm{T}_{\infty}\right)\right) \\
\mathrm{q}_{\text {ideal }}^{\mathrm{n}}=\mathrm{h} \sum_{\mathrm{i}=1}^{\mathrm{m}}\left(\mathrm{A}_{\mathrm{s}, \mathrm{i}}\left(\mathrm{T}_{\mathrm{b}}-\mathrm{T}_{\infty}\right)\right)=\mathrm{hA}_{\mathrm{s}}\left(\mathrm{T}_{\mathrm{b}}-\mathrm{T}_{\infty}\right)
\end{gathered}
$$

Fin efficiency is the ratio between the heat released by the real fin and the heat released if the temperature in the entire fin is equal to the base temperature of the fin (the maximum heat that can be released), which can be expressed by Equation (10).

$$
\eta^{\mathrm{n}}=\frac{\mathrm{q}_{\mathrm{aktual}}^{\mathrm{n}}}{\mathrm{q}_{\text {ideal }}}=\frac{\mathrm{h} \sum_{\mathrm{i}=1}^{\mathrm{m}}\left(\mathrm{A}_{\mathrm{s}, \mathrm{i}}\left(\mathrm{T}_{\mathrm{i}}^{\mathrm{n}}-\mathrm{T}_{\infty}\right)\right)}{\mathrm{h} \sum_{\mathrm{i}=1}^{\mathrm{m}}\left(\mathrm{A}_{\mathrm{s}, \mathrm{i}}\left(\mathrm{T}_{\mathrm{b}}-\mathrm{T}_{\infty}\right)\right)}=\frac{\sum_{\mathrm{i}=1}^{\mathrm{m}}\left(\mathrm{A}_{\mathrm{s}, \mathrm{i}}\left(\mathrm{T}_{\mathrm{i}}^{\mathrm{n}}-\mathrm{T}_{\infty}\right)\right)}{\left(\mathrm{A}_{\mathrm{s}}\right)\left(\mathrm{T}_{\mathrm{b}}-\mathrm{T}_{\infty}\right)}
$$

In Equations (8), (9), (10) we have the following conventions:

$\begin{array}{lll}\mathrm{q}_{\mathrm{aktual}}^{\mathrm{n}} & : \text { Actual heat released by the fin at the } \mathrm{n} \text { iteration, } \mathrm{W} \\ \eta^{\mathrm{n}} & : \text { Efficiency of the fin at the } \mathrm{n} \text { iteration } \\ \mathrm{m} & : \text { The number of control volumes } \\ \mathrm{h} & : \text { Convection heat transfer coefficient, } \mathrm{W} / \mathrm{m}^{2}{ }^{0} \mathrm{C} \\ \mathrm{T}_{\mathrm{i}} & : \text { Temperature of the control volume at position } \mathrm{i},{ }^{\circ} \mathrm{C} \\ \mathrm{T}_{\infty} & : \text { Fluid temperature around the fin, }{ }^{\circ} \mathrm{C} \\ \mathrm{T}_{\mathrm{b}} & : \text { Temperature of the base of the fin, }{ }^{\circ} \mathrm{C} \\ \mathrm{u}_{\infty} & : \text { Fluid velocity, } \mathrm{m} / \mathrm{s} \\ \mathrm{A}_{\mathrm{s}, \mathrm{i}} & : \text { Surface area of fin crossed by fluid for control volume in position } \mathrm{i}, \mathrm{m}^{2} \\ \mathrm{~A}_{\mathrm{s}} & : \text { Total surface area of the fin in contact with the fluid, } \mathrm{m}^{2} .\end{array}$

Fin effectiveness $\varepsilon^{n}$ is the ratio between the heat released by the actual fin and the heat released if there is no fin (or the fin length is zero), which can be expressed by Equation (11).

$$
\varepsilon^{n}=\frac{\left(\sum_{\mathrm{i}=1}^{\mathrm{m}}\left(\mathrm{A}_{\mathrm{s}, \mathrm{i}}\left(\mathrm{T}_{\mathrm{i}}^{\mathrm{n}}-\mathrm{T}_{\infty}\right)\right)\right)}{\mathrm{A}_{\mathrm{c}, \mathrm{i}}\left(\mathrm{T}_{\mathrm{b}}-\mathrm{T}_{\infty}\right)} .
$$




\section{Numerical Method}

\subsection{Research Object}

The research object is a straight fin in the form of a rotating object, as shown in the previous Figure 1. The initial condition of the fin is expressed by Equation (2). The basic condition of the fin is expressed by Equation (3), with $\mathrm{T}_{\mathrm{b}}=100^{\circ} \mathrm{C}$. The boundary condition at the fin end (fin tip) touches the fluid. Equation (6) is used to calculate the temperature at the fin tip. The fin length is $\mathrm{L}=0.1 \mathrm{~m}$. The diameter of the fin tip is $\mathrm{d}=0.0119936 \mathrm{~m}$. The diameter of the fin base is $\mathrm{D}=0.012 \mathrm{~m}$. The number of the control volumes is $m=101$. The space step (cell width) is $\Delta \mathrm{x}=0.001 \mathrm{~m}$. The initial temperature is uniform as $\mathrm{T}_{\mathrm{i}}=\mathrm{T}_{\mathrm{b}}=100^{\circ} \mathrm{C}$. The fluid temperature is $\mathrm{T}_{\infty}=30^{\circ} \mathrm{C}$. Variations in calculations include: (a) fin material, and (b) fluid velocity around the fin.

\subsection{Variations of the fin material}

For variations of fin material, we consider: (a) aluminum (b) zinc (c) iron (d) nickel and (e) copper. The properties of fin material are presented in Table 1, with the value of thermal conductivity being a function of temperature. The fluid that crosses the fin is water with a speed of $0.1 \mathrm{~m} / \mathrm{s}$.

Table 1. Fin material properties

\begin{tabular}{clccc}
\hline No & Material & $\boldsymbol{\rho}, \boldsymbol{k g} / \boldsymbol{m}^{\mathbf{3}}$ & $\boldsymbol{c}, \boldsymbol{J} / \boldsymbol{k g}^{\boldsymbol{o}} \boldsymbol{C}$ & $\boldsymbol{k}=\boldsymbol{k}(\boldsymbol{T}), \boldsymbol{W} / \boldsymbol{m}^{\boldsymbol{o}} \boldsymbol{C}$ \\
\hline 1 & Alumunium & 2707 & 896 & $k=0,0003 T 2+0,0074 T+202,23$ \\
2 & Zinc & 7897 & 384,3 & $k=-0,00008 T 2-0,0157 T+111,83$ \\
3 & Iron & 7144 & 452 & $k=0,00004 T 2-0,0791 T+74,309$ \\
4 & Nickel & 8906 & 445,9 & $k=0,00006 T 2-0,1103 T+92,602$ \\
5 & Copper & 8954 & 383,1 & $k=0,00001 T 2-0,06 T+385,62$ \\
\hline
\end{tabular}

\subsection{Variations of fluid velocity}

The fluid that crosses the fin is water. Variations in fluid velocity across the fins are selected for (a) $6 \mathrm{~m} / \mathrm{s}$, (b) $0.07 \mathrm{~m} / \mathrm{s}$, (c) $0.08 \mathrm{~m} / \mathrm{s}$, (d) $0.09 \mathrm{~m} / \mathrm{s}$, and (e) $0.1 \mathrm{~m} / \mathrm{s}$. For this case, the fin material is assumed to be aluminum.

\section{Results and Discussion}

To see the results of the calculation of the efficiency and effectiveness of the fin due to the influence of the fin material, calculations are carried out using the same type of fluid and flow velocity. In this calculation, the results of the calculation of the efficiency and effectiveness of the fin in unsteady state for some variations of the fin material are presented in Figure 3. From Figure 3 it appears that the efficiency and effectiveness are affected by the fin material. In unsteady state, the efficiency and effectiveness of the fin are influenced by density, specific heat and thermal conductivity of the fin. In other words, the value of thermal diffusivity which is a function of density, specific heat and thermal conductivity affect the efficiency and effectiveness of the fin. 
For $t>30$ seconds, or when the fin condition is already be said in steady state, the thermal conductivity of the fin material has an influence on the efficiency and effectiveness of the fin. Here the greater the thermal conductivity of the fin material, the smaller the efficiency and effectiveness of the fin. For the unsteady state (for example for $t<20$ seconds), density, specific heat and thermal conductivity of the fin material together have an effect on the value of the efficiency and the effectiveness of the fin. Therefore in this condition it cannot be stated that the greater the thermal conductivity value possessed by the fin material, the smaller the efficiency and effectiveness of the fin, because in our results, the order of efficiency and effectiveness is different.

Calculations to see the effect of fluid velocity across the fin on the efficiency and effectiveness of fins, are carried out using the same fin material and the same type of fluid. For fin efficiency and fin effectiveness, from Figure 4 we observe that for the velocity of the fluid that crosses the fin is $0.1 \mathrm{~m} / \mathrm{s}$, the fin efficiency and effectiveness are the lowest. For fluid velocity of $0.06 \mathrm{~m} / \mathrm{s}$, the fin efficiency and the effectiveness are greatest. We infer that if the fluid velocity across the fin increases, the efficiency and the effectiveness of the fin decreases. This is because the fluid velocity affects the amount of temperature distribution that occurs in the fin. The faster the fluid flow, the lower the temperature distribution that occurs in the fin. With the lower temperature distribution of the fin, the difference in fin temperature with the temperature of the fluid around the fin gets smaller. As a result, the rate of heat released by the fin is lower, because the convection heat transfer rate released by the fins is directly proportional to the temperature difference between the fin surface and the fluid temperature. The value of the fin efficiency and effectiveness will be lower too.

Actually the speed of fluid flow also affects the convection heat transfer coefficient. The faster the fluid flow, the greater the heat transfer coefficient. As a result, the heat released by the fin gets greater.

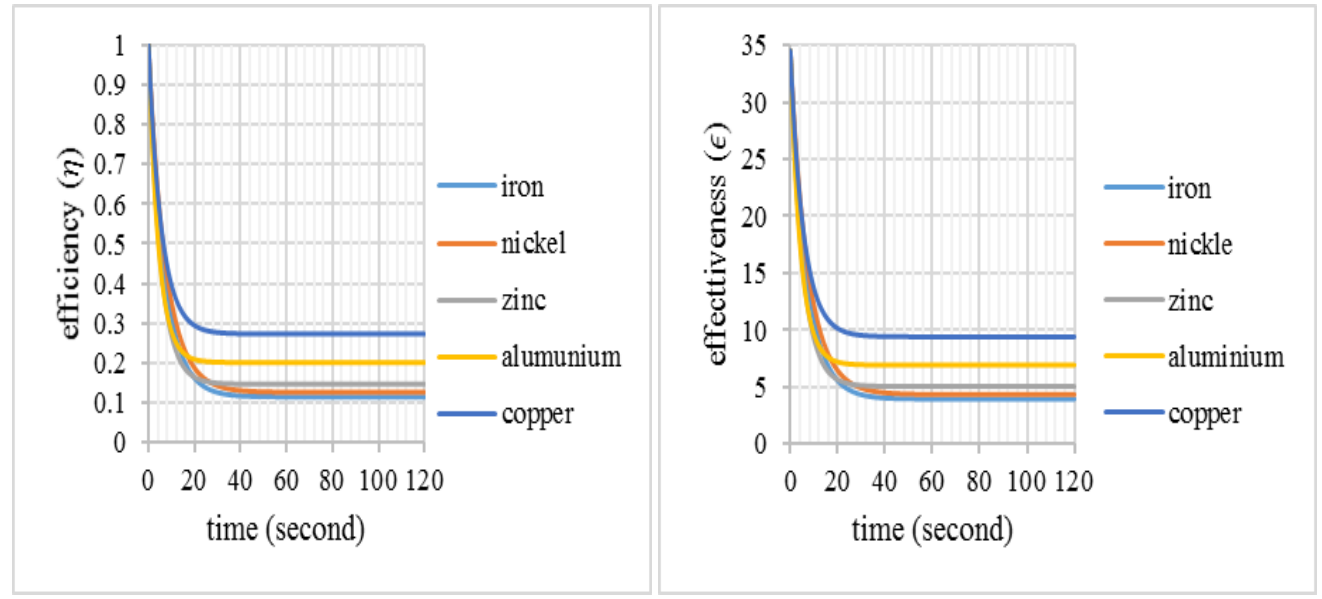

Fig. 3. Efficiency and effectiveness of the fin for variations of the fin material 


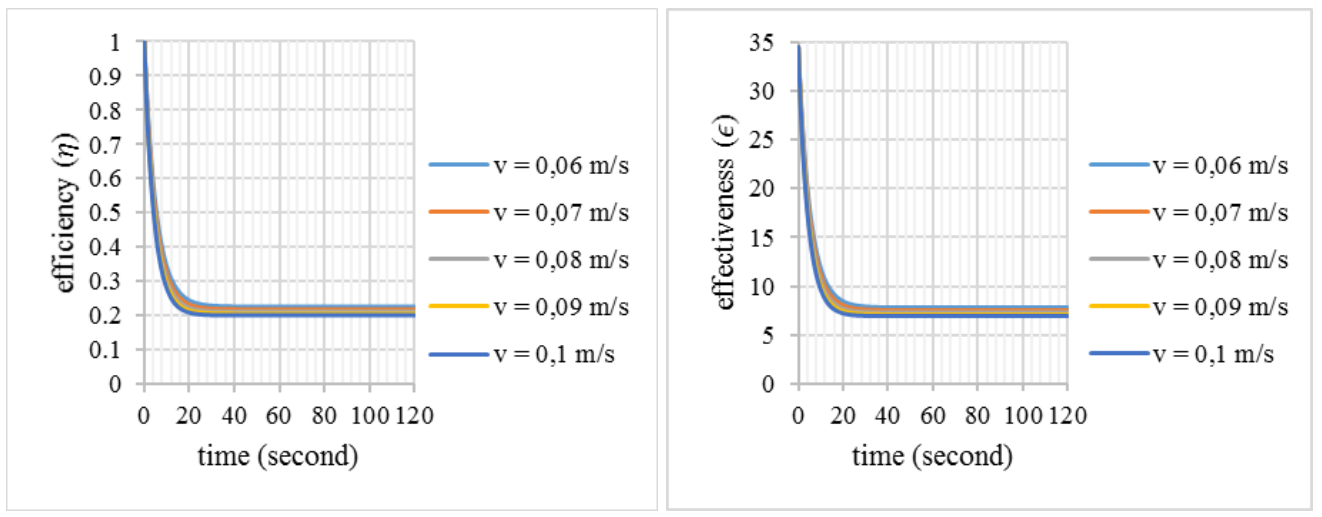

Fig. 4. Efficiency and effectiveness of the fin for variations of the fluid velocity

\section{Conclusion}

We draw some remarks as follows. In unsteady state, the efficiency and effectiveness of the fin are affected by the thermal diffusivity of the fin. In steady state, the efficiency and effectiveness of the fin are affected by the thermal conductivity of the fin. The velocity of the fluid across the fin influences the efficiency and effectiveness of the fin. That is, the greater the speed of fluid flow across the fin, the lower the efficiency and effectiveness of the fin.

Acknowledgments. The authors thank Universitas Sanata Dharma in supporting this research financially.

\section{References}

[1] Vantosa Y.A.: Efisiensi dan efektivitas sirip berbentuk benda putar dengan jari-jari fungsi posisi dan konduktivitas termal fungsi suhu kasus satu dimensi keadaan tak tunak (in Indonesian language). Undergraduate Thesis, Universitas Sanata Dharma, Yogyakarta (2018)

[2] Cengel, Y.A.: Heat Transfer: A Practical Approach. 2nd Edition. New York: McGrawHill (2003)

[3] Holman, J.P.: Heat Transfer. 10th Edition. New York: McGraw-Hill (2010)

[4] Purwadi P.K.: Efisiensi dan efektivitas sirip longitudinal dengan profil siku empat keadaan tak tunak kasus 2D (in Indonesian language). Seminar Nasional Aplikasi Sains dan Teknologi, IST Akprind, Yogyakarta (2008) 